\title{
Correction to: A novel agent-based model for tsunami evacuation simulation and risk assessment
}

\author{
Zhenqiang Wang ${ }^{1} \cdot$ Gaofeng Jia ${ }^{1}$ (i)
}

Published online: 7 January 2021

(c) Springer Nature B.V. 2021

\section{Correction to: Natural Hazards https://doi.org/10.1007/s11069-020-04389-8}

In the Abstract, the sentence "Usually, only single traffic mode (e.g., on foot or by car) is considered, while pedestrian speed adjustment and multi-modal evacuation (e.g., on foot and by car) are not considered concurrently." is not accurate, it should be changed to "While multi-modal evacuation (e.g., on foot and by car) has been proposed in the literature, typically pedestrian speed variability, pedestrian speed adjustment, and multi-modal evacuation are not considered concurrently."

In the first paragraph in Section 3, before the sentence "Several novelties are proposed and incorporated into the agent-based tsunami evacuation model.", the sentence "The agent-based tsunami evacuation model developed here extends on the agent-based modeling framework for a multimodal evacuation simulation under a near-field tsunami proposed by Wang and his co-workers at Oregon State University (Wang et al. 2016)." should be added for an explicit acknowledgement of existing work in the literature.

In Section 3.2.2, the sentence "Most of the tsunami evacuations are modeled using single traffic mode, e.g., either on foot or by car, which is not realistic." is not accurate and should be deleted.

At the end of Section 4.1, after "..., which makes the tsunami evacuation more complex.", the sentence "Therefore, Seaside has attracted a lot of attention, and there have been many tsunami evacuation studies focusing on Seaside, especially by researchers at Oregon State University (Wang et al. 2016; Mostafizi et al. 2017; Mostafizi et al. 2019)." should be added for an explicit acknowledgement of existing work in the literature.

The reference to the source of Figure 1a was missing, and "(USGS 2020)" should be added after the caption of Figure 1a. The updated caption of Figure 1 reads, "a Cascadia subduction zone (CSZ) (USGS 2020), and b Seaside, Oregon". The reference "(USGS 2020)" corresponds to:

The original article can be found online at https://doi.org/10.1007/s11069-020-04389-8.

Gaofeng Jia

Gaofeng.Jia@colostate.edu

1 Department of Civil and Environmental Engineering, Colorado State University, Fort Collins, CO, USA 
USGS (2020) Cascadia Subduction Zone. Retrieved from https://www.usgs.gov/media/ images/cascadia-subduction-zone-1.

Publisher's Note Springer Nature remains neutral with regard to jurisdictional claims in published maps and institutional affiliations. 